\title{
Subcellular distribution of GLUT 4 in the skeletal muscle of lean Type 2 (non-insulin-dependent) diabetic patients in the basal state
}

\author{
B. Vogt ${ }^{1}$, C.Mühlbacher ${ }^{1}$, J. Carrascosa ${ }^{3}$, B. Obermaier-Kusser ${ }^{1}$, E.Seffer ${ }^{1}$, J.Mushack $^{1}$, D.Pongratz $^{2}$ and H. U.Häring $^{1}$ \\ ${ }^{1}$ Institut für Diabetesforschung ${ }^{2}$ Friedrich-Baur Institut, München, FRG, and ${ }^{3}$ Universidad Autónoma de Madrid, Madrid, Spain
}

\begin{abstract}
Summary. Insulin resistance of the skeletal muscle is a key feature of Type 2 (non-insulin-dependent) diabetes mellitus. To determine whether a decrease of glucose carrier proteins or an altered subcellular distribution of glucose transporters might contribute to the pathogenesis of the insulin resistant state, we measured glucose transporter numbers in membrane fractions of gastrocnemius muscle of 14 Type 2 diabetic patients and 16 non-diabetic control subjects under basal conditions. Cytochalasin-B binding and immunoblotting with antibodies against transporter-subtypes GLUT 1 and GLUT 4 were applied. The cytochalasin-B binding values (pmol binding sites/g muscle) found in a plasma membrane enriched fraction, high and low density membranes of both groups (diabetic patients and non-diabetic control subjects) suggested a reduced number of glucose transporters in the plasma membranes of the diabetic patients compared to the control subjects (diabetic patients: $1.47 \pm 1.01$, control subjects: $3.61 \pm 2.29, p \leq 0.003$ ). There was no clear difference in cytochalasin-B binding sites in high and low density membranes of both groups (diabetic patients: high density mem-
\end{abstract}

branes $3.76 \pm 1.82$, low density membranes: $1.67 \pm 0.81$; control subjects: high density membranes $5.09 \pm 1.68$, low density membranes $1.45 \pm 0.90)$. By Western blotting analysis we determined the distribution of the glucose transporter subtypes GLUT 1 and GLUT 4 in the plasma membrane enriched fraction and low density membranes of seven patients of each group. In agreement with the cytochalasin-B binding data and despite a high variance within one group, the results show a clear decrease of GLUT 4 in the plasma membrane enriched fraction of diabetic patients compared to control subjects. In contrast, we found no difference in the distribution of GLUT 1 in diabetic patients and control subjects. In conclusion, despite a high variance of glucose transporter numbers in the skeletal muscle of different individuals fractionation of muscle samples clearly suggests that the number of GLUT 4 is reduced in the plasma membrane fraction of skeletal muscle of lean diabetic patients in the basal state.

Key words: Glucose transporter, human skeletal muscle, Type 2 diabetes.
Insulin resistance of target tissues characterizes Type 2 (non-insulin-dependent) diabetes mellitus [1-5]. The molecular defects causing the insulin resistant state are not yet completely understood. Recent studies have shown that an impaired insulin signalling mechanism at the level of the insulin receptor kinase of skeletal muscle, liver and fat contributes to the pathogenesis of insulin resistance in Type 2 diabetes [6-10]. It is not known whether other defects at the level of post-kinase signalling to cellular effector systems should be assumed. Furthermore, a possible dysfunction of one major effector system, the glucose transporter, is still controversially discussed. Garvey et al. reported that the number as well as the intrinsic activity of glucose carriers are reduced in adipose tissue of obese Type 2 diabetic patients [23]. The major part of the insulin-dependent postprandial glucose uptake occurs in the skeletal muscle and it is believed that an insulin resis- tance of the glucose transport system of the muscle [28] plays a central role in the development of Type 2 diabetes [1-5]. Glucose transporters exist in several isoforms (GLUT 1-5) [11-17]. The insulin effect on glucose transport appears to involve both translocation and activation of transporters [18-22]. A decreased expression and translocation of the GLUT 4 glucose transporter, but not of the GLUT 1 was found by Garvey et al. [29], Berger et al. [30], and Klip et al. [26,31] in fat and muscle of rats with streptozotozin-induced diabetes. In contrast to these animal data, Handberg et al. [32] and Pedersen et al. [33] in their recent studies did not find a significant alteration in the GLUT 4 number in human skeletal muscle of diabetic patients or control subjects in the basal state. Both studies determined total GLUT 4 numbers, therefore these data do not exclude the possibility of an altered distribution of transporters between plasma membranes and intracellu- 
lar membranes in diabetic patients. An altered distribution of GLUT 4, but not of GLUT 1 was indeed very recently described for the skeletal muscle of streptozotocindiabetic rats [26]. The aim of our study was to determine the glucose transporters in subcellular fractions of skeletal muscle of diabetic patients to elucidate whether despite normal total carrier numbers a reduction of the functionally important plasma membrane carrier fraction exists in diabetic patients.

\section{Subjects and methods}

\section{Materials}

Porcine $\left[{ }^{125} \mathrm{~T}_{-\mathrm{Tyr}}{ }^{\mathrm{A} 14}\right]$-insulin $(2200 \mathrm{Ci} / \mathrm{mmol})$ and $\left[{ }^{32} \mathrm{P}\right]$-ATP $(3000$ $\mathrm{Ci} / \mathrm{mmol}$ ), were obtained from New England Nuclear (Dreieich, FRG); aprotinin, phenylmethylsulfonylfluoride, poly (Glu 4:Tyr 1), leupeptin, pepstatin, benzamidin, bacitracin and leucine were obtained from Sigma (Munich, FRG). Wheat germ agglutinin coupled to agarose was obtained from Miles (Eschwege, FRG); Triton X100 , all reagents for sodium dodecyl sulphate (SDS) - polyacrylamide gel electrophoresis (PAGE) and the protein assay were from Bio Rad (Munich, FRG). For autoradiography X-Omat AR5 diagnostic film from Kodak (Rochester, NY, USA) was used. The Ultra Turrax was from IKA-Werk, Janke \& Kunkel KG, (Staufen i. Breisgau, FRG). Porcine insulin was purchased from Novo Industrie (Bagsvaerd, Denmark). The polyclonal serum directed against the C-terminal end of GLUT 4 was a kind gift of Dr. T.Ploug, Copenhagen, Denmark, the polyclonal serum against GLUT 1 was obtained from WAK-Chemie (Homburg, FRG), nitrocellulose from Schleicher and Schuell (Dassel, FRG), the chemiluminescence detective system was purchased from Amersham (Braunschweig, FRG).

\section{Selection of tissue samples}

Two groups of patients were chosen: one diabetic and one nondiabetic group of 60 - to 80 -year-old patients who underwent a leg amputation as a result of peripheral arteriovascular complications. Tissue specimens of musculus gastrocnemius were taken directly from the operating table, cut into small pieces (about $0.3 \mathrm{~g}$ ), immediately frozen in liquid nitrogen and stored at $-70^{\circ} \mathrm{C}$.
The muscle samples were used for further studies following a selection procedure which included the following criteria: (1) light microscopic, electron microscopic and histochemical qualities of the tissue, (2) enzymatic activity of lactate dehydrogenase EC 1.1.1.27, phosphofructo kinase EC 2.7.1.11, phosphoglycerate kinase EC 2.7.2.3 and phosphoglucomutase EC 2.7.5.1. and (3) non-collagen protein in the normal range for the muscle tissue.

Methods for histological, histochemical and morphometric examination as well as for measuring muscle enzyme activities have been previously described in detail [10].

\section{Insulin and glucose levels in patient serum}

Insulin levels were determined in morning serum samples of all patients by the commercially available insulin ELISA EnzymunTest Insulin from Boehringer, Mannheim, (Mannheim, FRG) on the automated ELISA-machine ES22, also from Boehringer, Mannheim.

Glucose levels were measured in samples taken into standard tubes containing sodium fluoride from Sarsted (Ulm, FRG) using the glucose-dehydrogenase-method Granutest 250 from Merck (Darmstadt, FRG), and the enzyme analyser ACP 5040 from Eppendorf (Hamburg, FRG). Means were then calculated for each patient.

\section{Subcellular fractionation of skeletal muscle}

To prepare plasma and microsomal membrane fractions approximately $3-4 \mathrm{~g}$ muscle were minced by an Ultra Turrax $(2 \times 20$ s) on ice in $20 \mathrm{ml}$ buffer containing $10 \mathrm{mmol} / \mathrm{l} \mathrm{NaHCO}, 5 \mathrm{mmol} / 1 \mathrm{NaN}_{3}$ at pH 7. The muscle homogenate was then pottered ten times for $10 \mathrm{~s}$ in a Teflon/glass potter. The homogenate was then further treated as described in the flow sheet (Fig. 1) using a TES-buffer containing $2 \mathrm{mmol} / \mathrm{l}$ Tris, $1 \mathrm{mmol} / \mathrm{l}$ EDTA, $255 \mathrm{mmol} / \mathrm{l}$ sucrose, $10 \mu \mathrm{g} / \mathrm{ml}$ aprotinin, $1 \mathrm{mmol} / \mathrm{l}$ phenylmethylsulfonylfluoride, $0.2 \mathrm{mg} / \mathrm{ml}$ bacitracine, $0.2 \mathrm{mg} / \mathrm{ml}$ benzamidine, $100 \mathrm{mmol} / \mathrm{s}$ sodiumfluoride, $10 \mathrm{mmol} / \mathrm{l}$ tetra-sodium diphosphate decahydrate, $1 \mathrm{mmol} / 1$ vanadate at $\mathrm{pH}$ 7.4. To obtain the high density fraction the first pellet of the procedure leading to low density membranes was again resuspended and centrifuged for $30 \mathrm{~min}$ at $30000 \times \mathrm{g}$. For all other details see Figure 1 . The reproducibility of the fractionation procedure was assessed by measuring the ouabain-sensitive $\mathrm{Na} / \mathrm{K}$ ATPase (enriched in plasma membrane fraction), rotenone-insensitive NADHcytochrome $\mathrm{C}$ reductase activity (enriched in endoplasmic-reticu-

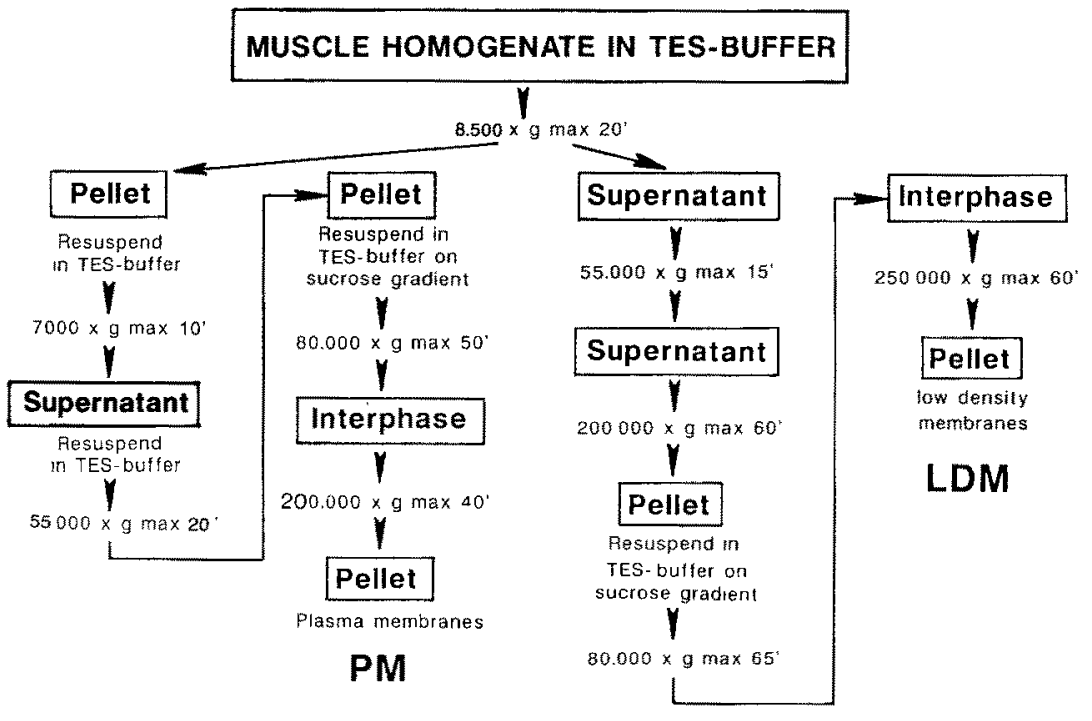

Fig. 1. Flow sheet describing the muscle homogenates which were prepared in different volumes of TES-buffer. Plasma membranes (PM): 20 ml TES for resuspending the first and second pellet, $2 \mathrm{ml}$ for the third pellet. Low density membranes (LDM): $9 \mathrm{ml}$ for resuspending the first pellet. High density membranes (HDM): $25 \mathrm{ml}$ for resuspending the pellet of the centrifugation step of $55000 \times g$ max 15 min (not shown) 


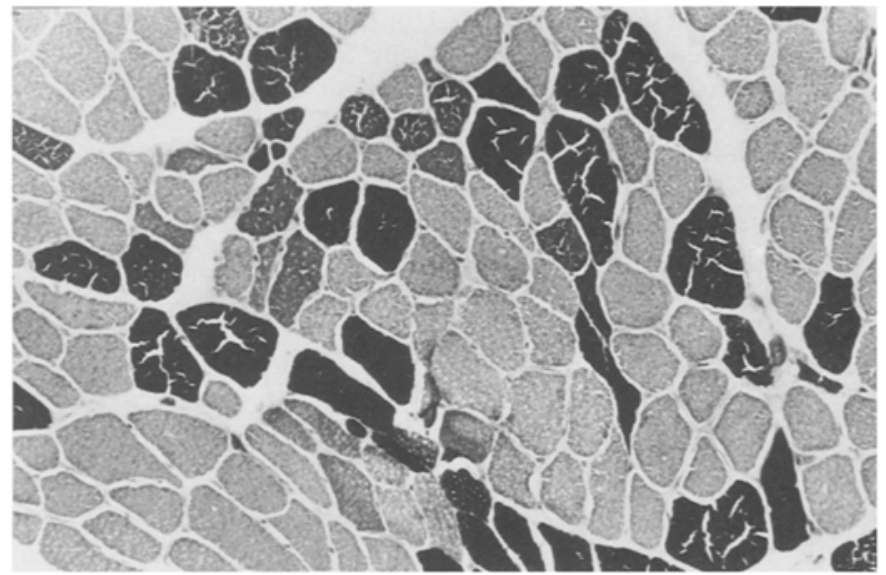

Fig. 2. Characterization of muscle tissue samples. Panel A shows a representative enzyme histochemical preparation from non-diabetic (left) and diabetic (right) $\mathrm{m}$. gastrocnemius $(100 \times)$. Tissue was stained with myofibrillic ATPase (pH 9.4). The bright cells are type I

lum fraction) and uridine diphosphate (UDP)-galactosyl-transferase activity (enriched in Golgi apparatus) of each fraction and in the original homogenates $[34,35]$. Protein concentration was determined by the Bio-Rad assay.

\section{Cytochalasin- $B$ binding $(C B B)$ assay}

The concentration of D-glucose transporters in the membrane fractions was assessed using a specific D-glucose-inhibitable CBB assay, developed by Wardzala and Cushman [18] and modified by Karnieli [36]. The CBB assay was carried out as outlined by Mühlbacher et al. [20]. Briefly, in each assay we used 11 different cytochalasin-B concentrations $\left(2 \times 10^{-8}-4 \times 10^{-7} \mathrm{~mol} / \mathrm{l}\right)$ in the test. ${ }^{14} \mathrm{C}$-urea was used to determine trapped, unbound ${ }^{3} \mathrm{H}$-cytochalasin $\mathrm{B}$ in the pelleted membranes, obtained during the binding assay. Therefore it was added in equivalent proportion of final ${ }^{14} \mathrm{C}$ to the concentration of ${ }^{3} \mathrm{H}$-cytochalasin $\mathrm{B}$. From the resulting 11 point $\mathrm{CBB}$ curves the number of glucose inhibitable binding sites and the affinity constants were determined by Scatchard analysis.

\section{Western blotting}

Western blotting was performed as recently described elsewhere $[37$, 38]. Membranes ( $10 \mu \mathrm{g}$ protein) were subjected to SDS-PAGE on a $7.5 \%$ gel in the presence of $10 \mathrm{mmol} / \mathrm{l}$ dithiothreitol using the system

Table 1. Patient characteristics

\begin{tabular}{lllll}
\hline $\begin{array}{l}\text { Patient Muscle } \\
\text { Group }\end{array}$ & $n$ & $\begin{array}{l}\text { Age } \\
\text { (years) }\end{array}$ & $\begin{array}{l}\text { BMI } \\
\left(\mathrm{kg} / \mathrm{m}^{2}\right)\end{array}$ & $\begin{array}{l}\text { Fasting serum } \\
\text { Glucose Insulin } \\
(\mathrm{mmol} / /)(\mu \mathrm{U} / \mathrm{ml})\end{array}$
\end{tabular}

\begin{tabular}{lllllll}
\hline 1 & $\begin{array}{l}\text { Non-diabetic } \\
\text { gastrocnemius }\end{array}$ & 16 & $67 \pm 3$ & $23 \pm 2$ & $6 \pm 0.4$ & $16 \pm 6$ \\
2 & $\begin{array}{l}\text { Type 2 diabetic } 14 \\
\text { gastrocnemius }\end{array}$ & $72 \pm 4$ & $23 \pm 1$ & $10 \pm 1.1$ & $25 \pm 5$ \\
\hline
\end{tabular}

The fasting glucose levels for each patient are mean values of three to four morning glucose measurements during clinical treatment; fasting insulin levels were obtained from one serum sample taken in the morning before breakfast, $2-3$ weeks after the amputation when the patients were no longer on bed rest (all data given as means \pm SEM)

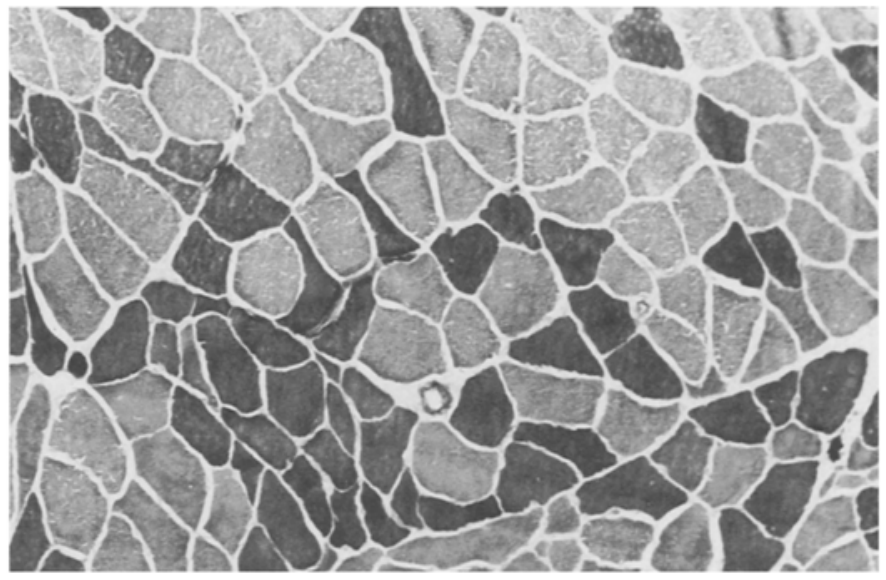

(red) muscle fibres, and the dark cells are type II (white) muscle fibres. The pictures show neurogenic atrophy especially in type II fibres and type-grouping of the type I fibres.

of Laemmli. Proteins were transfered to nitrocellulose by electroblotting (buffer: $192 \mathrm{mmol} / \mathrm{l}$ glycine, $25 \mathrm{mmol} / \mathrm{l}$ Tris, $20 \% \mathrm{MeOH}$, pH 8.3, $3 \mathrm{~h}, 200 \mathrm{mAmpere).} \mathrm{Following} \mathrm{transfer,} \mathrm{the} \mathrm{filters} \mathrm{were}$ blocked with $5 \%$ non-fat dry milk in phosphate-buffered saline (PBS) for $1 \mathrm{~h}$ at $37^{\circ} \mathrm{C}$ and subsequently incubated with the first antibody (dilution in PBS, $1 \%$ dry milk) overnight at $4^{\circ} \mathrm{C}$. After mcubation with the specific antibody, nitrocellulose was washed several times in Tris-buffered saline ( $20 \mathrm{mmol} / \mathrm{Tris}, 150 \mathrm{mmol} / \mathrm{NaCl}, 2.5 \%$ non-fat dry milk, $1 \%$ Triton X-100). Anti-rabbit horseradish peroxidase labelled IgG was bound to the immuncomplexes and visualization of the immunolabelled bands was carried out by addition of a chemiluminescence reagent followed by autoradiography.

\section{Statistical analysis}

CBB data from subcellular membrane fractions of normal and diabetic human skeletal muscle were compared using an unpaired Student's $t$-test. Differences between the two groups were accepted as significant for $p \leq 0.01$, and as not significant for $p>0.01$.

\section{Results}

\section{The selection of skeletal muscle biopsies}

Muscle samples were collected from Type 2 diabetic patients and non-diabetic control subjects. After the selection procedure described below, 16 control subjects and 14 diabetic patients were eventually included in the study. The clinical characteristics of these patients are shown in Table 1.

Muscle samples from non-diabetic and diabetic patients were characterized by morphological and biochemical criteria. First the physiological integrity of the tissue was assessed by light microscopy. In addition to the morphological criteria, muscle enzyme activities were determined to assess the functional integrity of the samples and to exclude unspecific effects due to tissue ischaemia. Therefore the activities of lactate dehydrogenase, phosphoglycerate kinase, phosphoglucomutase and phosphofructokinase (which is particularly sensitive to ischaemia) 


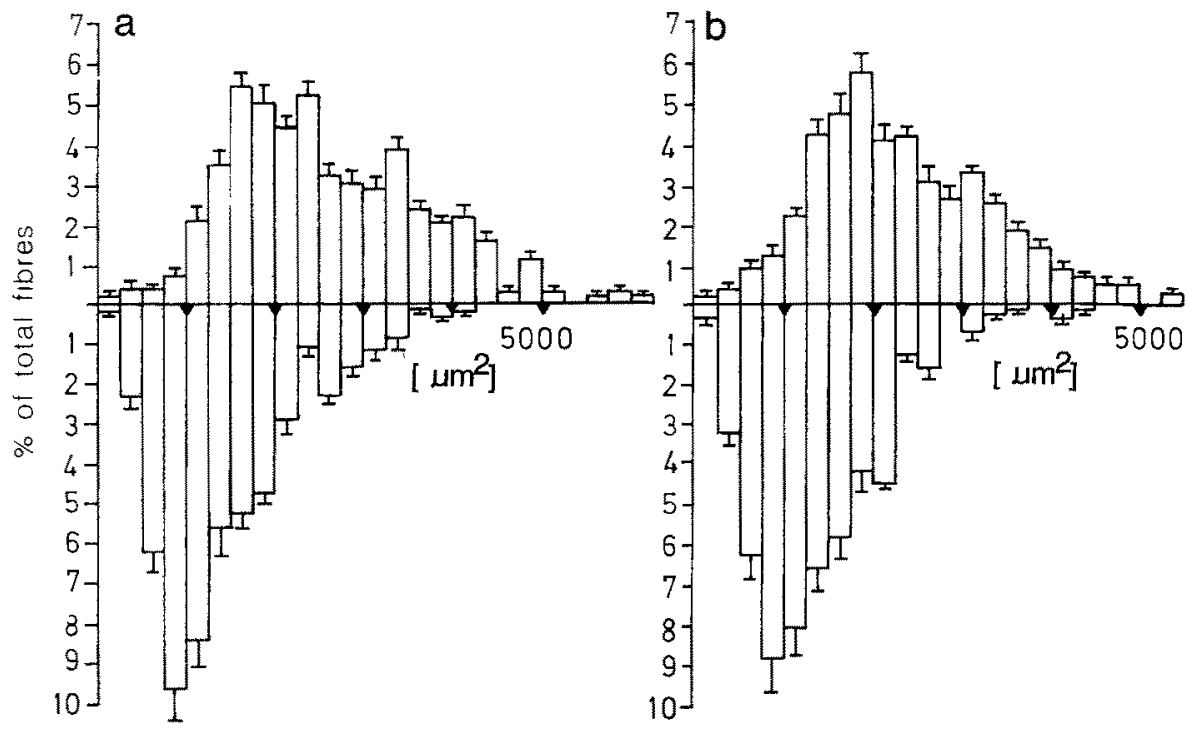

Fig. 3a, b. Histograms of square sections of $m$. gastrocnemius from non-diabetic (a, $n=10)$ and diabetic $(\mathbf{b}, n=12)$ patients are shown. Square dimension for a single muscle fibre square section was determined as mean of the maximal and minimal diameter. All fibres of a representative area containing 200 red and white fibres were evaluated, the diameters are grouped in classes of a width of $250 \mu \mathrm{m}^{2}$. Mean $\pm \mathrm{SD}$ of each square dimension class from 0 to $6000 \mu \mathrm{m}^{2}$ for red (upper part) and white muscle fibres (lower part) are shown for the two patient groups

Table 2. Muscle enzyme activities and non-collagen protein (NCP) levels for patients admitted to the study

\begin{tabular}{lcc}
\hline Enzyme & $\begin{array}{l}\text { Non-diabetic } \\
\text { Muscle } \\
\text { (Group 1) }\end{array}$ & $\begin{array}{l}\text { Type 2 diabetic } \\
\text { Muscle } \\
\text { (Group 2) }\end{array}$ \\
\hline Lactate dehydrogenase & U/g NCP & U/g NCP \\
Phosphofructo kinase & $1059 \pm 78$ & $969 \pm 112$ \\
Phosphoglycerate kinase & $837 \pm 13$ & $129 \pm 12$ \\
Phosphoglucomutase & $1005 \pm 81$ & $920 \pm 83$ \\
& mg/g muscle & mg/g muscle \\
Non-collagen protein & $78 \pm 18$ & $72 \pm 10$ \\
\hline
\end{tabular}

The enzyme activities were measured twice for each patient as described in Subjects and methods. The units of activity were normalized for NCPs. Muscle samples with activities which were not within the given range were excluded from further characterization

Table 3. Protein recovery, distribution of marker enzyme specific activities and activity ratios in subcellular membrane fractions from skeletal muscle

\begin{tabular}{|c|c|c|c|}
\hline Membrane fractions & $\begin{array}{l}\text { Plasma } \\
\text { membranes }\end{array}$ & $\begin{array}{l}\text { Low density } \\
\text { membranes }\end{array}$ & $\begin{array}{l}\text { High density } \\
\text { membranes }\end{array}$ \\
\hline $\begin{array}{l}\text { NADH-cytochrom C } \\
\text { reductase }\left(\mathrm{nmol} \cdot \mathrm{min}^{-1}\right. \\
\cdot \text { mg of protein } \\
-1)\end{array}$ & $0.20 \pm 0.02$ & $0.13 \pm 0.01$ & $0.35 \pm 0.03$ \\
\hline Activity ratio (\%) & 57 & 37 & 100 \\
\hline $\begin{array}{l}\text { Ouabain sensitive } \\
\mathrm{Na} / \mathrm{K}-\mathrm{ATP} \text { ase (nmol Pi } \\
\mathrm{min}^{-1} \cdot \mathrm{mg} \text { of protein } \\
\end{array}$ & $124.2 \pm 11.7$ & $69.8 \pm 11.1$ & $67.3 \pm 7.3$ \\
\hline Activity ratio (\%) & 100 & 56 & 54 \\
\hline $\begin{array}{l}\text { UDP-galactosyltrans- } \\
\text { ferase }\left(\text { nmol } \cdot \min ^{-1} \text {. }\right. \\
\left.\text { mg of protein }{ }^{-1}\right)\end{array}$ & $1.23 \pm 0.33$ & $2.18 \pm 0.57$ & $1.16 \pm 0.22$ \\
\hline Activity ratio (\%) & 56 & 100 & 53 \\
\hline \multicolumn{4}{|c|}{$\begin{array}{l}\text { Results are expressed as the mean } \pm \text { SEM of } 10-15 \text { experiments. Ac- } \\
\text { tivity ratios are calculated by setting the specific activity of the most } \\
\text { enriched membrane fraction at } 100 \% \text { and those in other membrane } \\
\text { fractions relative to that specific value. Compared to the values } \\
\text { found in the crude homogenate plasma membranes were enriched } \\
14.0 \text { times, low density membranes } 4.1 \text { times } \\
\text { UDP, uridine diphosphate }\end{array}$} \\
\hline
\end{tabular}

were measured. Furthermore the amount of non-collagen protein was determined. Samples which showed signs of ischaemia or enzyme abnormalities were exluded and only normal tissue was further used. The selected skeletal muscle samples belong to two groups: Group 1, composed of 16 muscle samples obtained from musculus gastrocnemius of non-diabetic subjects and Group 2, composed of 14 gastrocnemius samples from diabetic patients; patients in both groups underwent leg amputation.

The fibre composition of the selected muscle samples was determined histologically (Fig.2). There was no difference in fibre composition, number and size between diabetic and control patients (Fig.3). There was also no difference in muscle enzyme activities between these groups (Table 2).

\section{Cytochalasin- $B$ binding $(C B B)$ assay}

Membrane fractions were prepared as described in Subjects and methods above. To assess the purity of the membrane preparations, marker enzymes were determined and the results are shown in Table $3 . \mathrm{Na} / \mathrm{K}$-ATPase was determined as a marker enzyme for plasma membranes. NADH-cytochrome C reductase was employed as marker for the high density membrane fraction and UDP-galactosyl-transferase as marker for the low density membrane fraction. Using human skeletal muscle we were unable to obtain the purity of the fractions which we had earlier found in rat fat cells [20] and in rat skeletal muscle and rat heart (unpublished data). The cross contamination of membrane fractions from human muscle is considerably higher. CBB was determined in the plasma membrane enriched fraction, high density membranes and low density membranes from the skeletal muscle samples of the different patient groups. Figure 4 shows a derived Scatchard plot of CBB binding to all three membrane fractions for one representative non-diabetic control subject and one diabetic patient. Transporter numbers and affinities were determined for each patient separately in this way by 


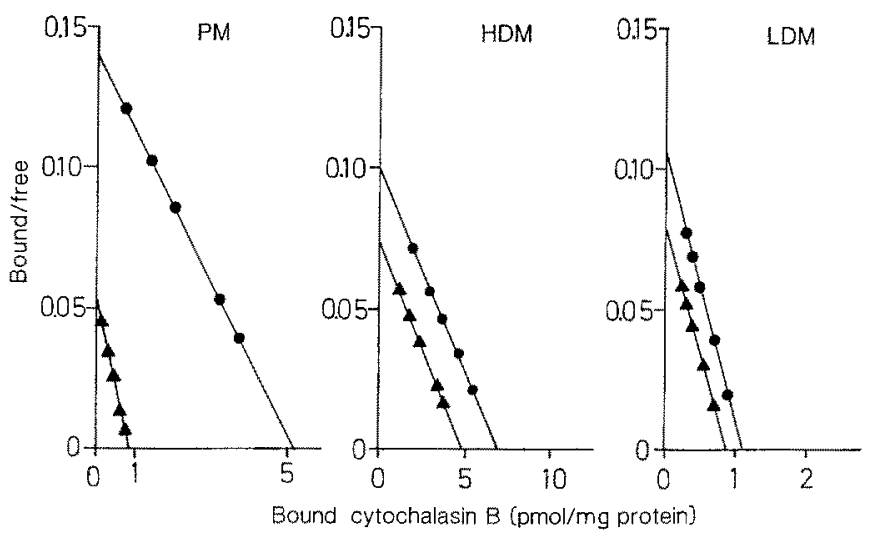

Fig.4. Scatchard analysis of $\left[{ }^{3} \mathrm{H}\right]$-cytochalasin-B-binding to skeletal muscle membranes isolated from normal (-) and Type 2 (non-insulin-dependent) diabetic ( $\boldsymbol{A}$ ) muscle tissue. Membranes were prepared as described in Subjects and methods. A representative Scatchard-plot of cytochalasin-B-binding for one diabetic and one non-diabetic patient is shown. The mean dissociation constants (nmol/1) of all patients studied were as follows: PM control subjects $83.8 \pm 8.5 \mathrm{SEM}$, diabetic patients $61.7 \pm 7.3 \mathrm{SEM}$. HDM control subjects 69.2 \pm 5.9 SEM, diabetic patients $66.7 \pm 8.8$ SEM. LDM control subjects $44.8 \pm 5.3 \mathrm{SEM}$, diabetic patients $50.2 \pm 8.5$ SEM. PM, Plasma membranes; HDM, High density membranes; LDM, Low density membranes

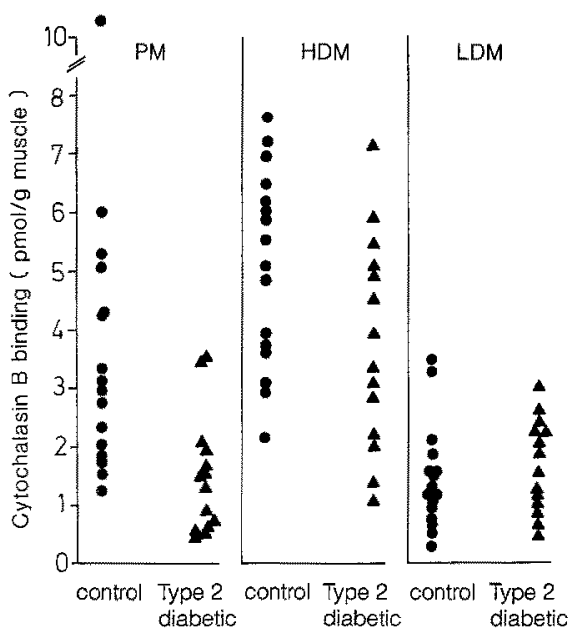

Fig.5. Glucose carrier numbers in plasma membranes (PM), high density membranes (HDM) and low density membranes (LDM) of Type 2 (non-insulin-dependent) diabetic skeletal muscle and nondiabetic skeletal muscle. Cytochalasin-B binding sites resulting from derived Scatchard plots are shown from 16 control subjects (•) and 14 Type 2 diabetic patients ( $\boldsymbol{A}$ )

CBB-Scatchard plots. There was no significant difference in affinity values for transporters from non-diabetic skeletal muscle and diabetic skeletal muscle. The individual transporter numbers as determined by derived Scatchard plots are shown for all 14 diabetic and 16 control subjects in Figure 5. To exclude an influence of a "day to day" variation we always performed at least one diabetic muscle preparation in parallel to one non-diabetic control on the same day with all preparation steps done in parallel. Furthermore, when enough muscle was available, the membrane preparation was repeated once for this patient. The variation of different preparations for the same patient was below $5 \%$. The diabetic plasma membranes contained a lower range of CBB-sites than the corresponding normal preparations while in the low density membrane enriched fraction and in the high density membrane enriched fraction similar values were found. The mean values for the plasma membrane enriched fraction were $3.61 \pm 2.29 \mathrm{pmol}$ binding sites $/ \mathrm{g}$ muscle for control subjects and $1.47 \pm 1.01 \mathrm{pmol}$ binding sites/g muscle for diabetic patients. If the CBB-values in the diabetic patients are expressed as percentage of their normal control prepared in parallel, a mean value of $43.8 \pm 5.0 \%$ ( $n=29$ parallel preparations) in the plasma membrane enriched fraction is found, while the same calculation for the high and low membrane enriched fractions revealed values of $78.4 \pm 8.9 \%(n=23$ parallel preparations $)$ and $153.1 \pm 27.7 \%$ ( $n=18$ parallel preparations $)$, respectively. The difference in plasma membranes is statistically significant $(p=0.003)$ while there is no significant difference for high density $(p=0.048)$ and low density $(p=0.504)$ membrane enriched fractions.

\section{Western blotting}

To study the distribution of different glucose transporter subtypes we performed Western blotting with subcellular membrane fractions of the muscle samples of seven patients of each group and specific antibodies against two different glucose transporter subtypes, GLUT 1 and GLUT 4. An equal amount of protein $(10 \mu \mathrm{g})$ of the plasma membrane enriched fraction and the LDM-enriched fraction was subjected to SDS-PAGE, immunoblotted, and incubated with a chemiluminescence reagent to visualize the specific $45 \mathrm{kDa}$ glucose transporter band. Figure 6 shows autoradiographs of plasma membranes of

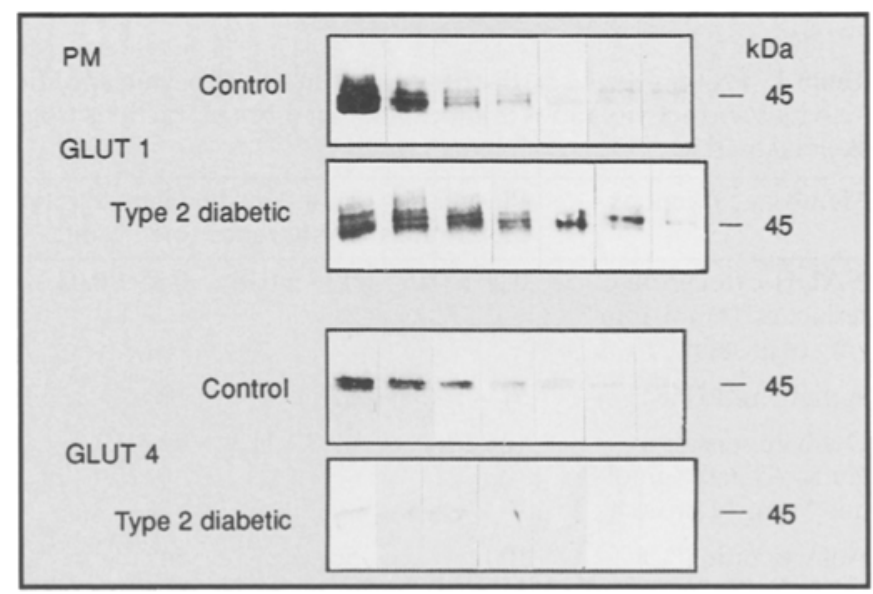

Fig. 6. Western blot analysis of plasma membranes (PM) of seven control subjects and seven Type 2 (non-insulin-dependent) diabetic patients with antibodies against GLUT 1 (upper panel) and GLUT 4 (lower panel). The blots were quantified by scanning densitometry. The following relative values were obtained: From left to right upper panel (GLUT 1):

Control subjects: $2922,1705,768,528,263,144,132$

Diabetic patients: 2042, 1741, 1500, 1382,891, 503, 62

From left to right lower panel (GLUT 4):

Control subjects: $676,468,279,126,98,58,44$

Diabetic patients: $138,69,73,25,21,15,10$ 


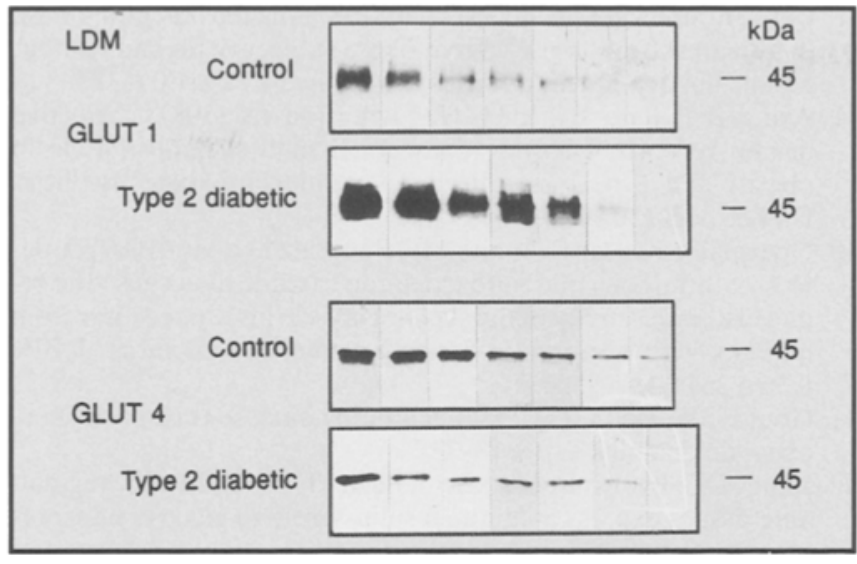

Fig. 7. Western blot analysis of low density membranes (LDM) of seven control subjects and seven Type 2 (non-insulin-dependent) diabetic patients with antibodies against GLUT 1 (upper panel) and GLUT 4 (lower panel). The blots were quantified by scanning densitometry. The following relative values were obtained: From left to right upper panel (GLUT 1):

Control subjects: $1000,309,238,170,31,20$

Diabetic patients: $1717,980,662,843,464,13,10$

From left to right lower panel (GLUT 4):

Control subjects: $799,688,416,209,100,46,13$

Diabetic patients: $815,300,57,44,30,13,10$

seven diabetic patients and seven control subjects immunoblotted either with antibodies against GLUT 1 or GLUT 4. Each band represents one patient, respectively one control subject. As both groups showed a high interindividual variation autoradiographs are arranged according to the intensity of the glucose transporter bands. Whereas the intensity of the GLUT 1 bands revealed no obvious difference between the control group and diabetic patients the GLUT 4 autoradiographs show a decrease of GLUT 4 labelling in diabetic samples compared to control subjects. The autoradiographs of the low density membrane enriched fraction are shown in Figure 7. No obvious difference in range is seen in either GLUT 1 labelling or in GLUT 4 labelling.

\section{Discussion}

The data of both methods, the CBB assay and the Western blotting, show in the basal state a decreased range of glucose transporters specifically GLUT 4 in a plasma membrane enriched fraction of skeletal muscle in diabetic patients. No major difference in GLUT 1 distribution is seen. This result is in good agreement with rat skeletal muscle data $[26,39,40]$. It is, however in contrast to the studies of Pedersen et al. [33] and Handberg et al. [32] in human muscle. One possible explanation for the discrepancy is the different source of the muscle samples, which was musculus vastus lateralis in these studies $[32,33]$ and musculus gastrocnemius in our study. Furthermore differences of the age of the study groups might be important. The difference might also be explained by the fractionation procedure. Fractionation might, on the one hand, be necessary to unmask a small difference which is not detected when unfractionated material is used. On the other hand, fractionation is a possible source of artefacts. To evaluate the significance of these results a possible influence of sample selection and tissue conditions should also be discussed.

To characterize the glucose carrier numbers after fractionation of subcellular membranes, greater amounts of skeletal muscle are required than those which can be obtained with needle biopsies. To use muscle samples from leg amputation is an experimental possibility which solves the problem of tissue quantity. On the other hand, it restricts the study to a characterization of the basal state as all patients are operated after the usual fasting period. A major concern, however, using such tissue samples is to avoid a possible influence of chronic tissue ischaemia. To assess an influence of chronic ischaemia we measured the activity of several enzymes. In particular phosphofructokinase is known to be very sensitive to ischaemia. As there is no difference in these enzyme activities between Groups 1 and 2 ischaemia might be excluded as an explanation for the observed lack of glucose carriers in the diabetic population. There was also no difference concerning all other muscle enzymes examined or the different membrane enzymes which were used as marker enzymes between the two groups. Similarly the ratio of type I and type II fibres as well as their morphological characteristics were not different between diabetic and non-diabetic subjects. As a further control we determined ${ }^{125} \mathrm{I}$-insulin binding in plasma membranes from diabetic patients and control subjects, with no difference shown between the groups (data not shown). A further mechanism which could influence the results of glucose carrier determination is the quality of the membrane preparation. The preparation of membrane fractions from skeletal muscle is known to be considerably more difficult than the membrane preparation from fat cells [20]. Despite the modified preparation procedure applied here the impurity of the different membrane fractions as determined by the distribution of marker enzymes is still considerably high. However, it is important to note that there is no significant difference in protein recovery or cross-contamination of the different membrane fractions between the control and diabetic group. Therefore, cross-contamination cannot explain the reduced number of glucose carriers found in the diabetic plasma membrane fraction. It is evident that both the control and the diabetic groups show a high variation of GLUT 4 as well as GLUT 1 labelling. While the range of GLUT 1 is widely superimposable between control subjects and diabetics, the range of GLUT 4 in the plasma membrane fraction is significantly decreased in diabetic patients. The individual variation in both groups is surprising. However, such a high individual variation in normal subjects and diabetic patients was also seen in other studies [28] suggesting that indeed a high variation of the individual capacity of the glucose transport system already exists in normal control subjects.

The discussion of the pathophysiological relevance of our data is limited by the following problems: 1) The data were obtained in the fasting state and it is unclear whether the lower range of plasma membrane GLUT 4 would still be found in the insulin-stimulated state which is clearly the more important situation for the pathogenesis of Type 2 
diabetes. 2) It is not entirely clear whether in human skeletal muscle plasma membrane GLUT 4 numbers represent the relevant fraction which determines the glucose transport rate.

There are no human data published which provide the basis for the first problem to be answered. The published data concerning the second problem are controversial. Based on animal studies two different models for the insulin stimulation of the glucose transport in skeletal muscle are proposed. Some authors favour a combined model of carrier translocation and activation as it is widely accepted for the fat cell [24-26], while others suggest that in the skeletal muscle only carrier activation occurs [27]. Klip et al. [24-26] studied subcellular fractions of rat skeletal muscle in the basal and insulin-stimulated state and found an insulin-dependent increase of GLUT 4 labelling in the plasma membrane fraction and a decrease in the LDM-fraction suggesting that the plasma membrane fraction of GLUT 4 is the relevant factor controlling glucose uptake. In contrast to this in a recently conducted morphological approach Friedman et al. [39] did not see any immunolabelling of GLUT 4 in plasma membranes of human skeletal muscle either under basal or under insulin-stimulated conditions. According to their observations glucose transport may occur across the transverse tubule membrane and glucose transporters are possibly translocated to this membrane system from an intracellular pool.

In summary, further studies defining the mechanism of insulin action on the transporters in human skeletal muscle are required before it will be possible to evaluate a potential contribution of an abnormality of the muscle glucose transport system to the pathogenesis of insulin resistance.

Acknowledgements. This study was supported by grants from the Thyssen Stiftung and the DFG.

\section{References}

1. DeFronzo RA, Simonson D, Ferrannini E (1982) Hepatic and peripheral insulin resistance: a common feature of Type 2 (noninsulin-dependent) and Type 1 (insulin-dependent) diabetes mellitus. Diabetologia 23: 313-319

2. Jackson RA, Roshania RD, Sim BM, DiSilvio L (1986) Impact of glucose ingestion on hepatic and peripheral glucose metabolism in man: an analysis based on simultaneous use of the forearm and double isotope technique. J Clin Endocrinol Metab 63: 541-549

3. Olefsky JM, Ciaraldi TP, Kolterman OG (1985) Mechanism of insulin resistance in non-insulin-dependent (type II) diabetes. Am J Med 79: 12-22

4. Reaven GM, Chen YI, Coulston AM et al. (1983) Insulin secretion and action in non-insulin-dependent diabetes mellitus. Am J Med 75: 85-93

5. Rizza RA, Mandarino LJ, Gerich JE (1981) Mechanism and significance of insulin resistance in non-insulin-dependent diabetes mellitus. Diabetes 30: 990-995

6. Freidenberg GR, Henry RR, Klein HH, Reichart DR, Olefsky JM (1987) Decreased kinase activity of insulin receptors from adipocytes of non-insulin-dependent diabetic subjects. J Clin Invest $79: 240-250$

7. Häring HU, Obermaier B, Ermel B et al. (1987) Insulin receptor kinase defects as a possible cause of cellular insulin resistance. Diab Metab 13: 284-293
8. Caro JF, Sihna MK, Raju SM et al. (1987) Insulin receptor kinase in human skeletal muscle from obese subjects with and without noninsulin dependent diabetes. J Clin Invest 79: 1330-1337

9. Arner P, Pollare T, Lithell H, Livingston JN (1987) Defective insulin receptor tyrosine kinase in human skeletal muscle in obesity and Type 2 (non-insulin-dependent) diabetes mellitus. Diabetologia $30: 437-440$

10. Obermaier-Kusser B, White MF, Pongratz D et al. (1989) A defective intramolecular autoactivation cascade may cause the reduced kinase activity of the skeletal muscle insulin receptor from patients with non-insulin-dependent diabetes mellitus. J Biol Chem 264:9497-9504

11. Gould GW, Bell GI (1990) Facilitating glucose transporters: an expanding family. TIBS: $18-23$

12. James DE, Brown R, Navarro J, Pilch PF (1988) Insulin-regulat able tissues express a unique insulin-sensitive glucose transport protein. Nature 333: 183-185

13. Birnbaum MJ, Haspel HC, Rosen OM (1986) Cloning and characterization of a cDNA encoding the rat brain glucose-transporter protein. Proc Natl Acad Sci USA 83: 5784-5788

14. James DE, Strube M, Mueckler M (1989) Molecular cloning and characterization of an insulin-regulatable glucose transporter. Nature 338: 83-87

15. Zorzano A, Wilkinson W, Kotliar $\mathrm{N}$ et al. (1989) Insulin-regulated glucose uptake in rat adipocytes is mediated by two transporter isoforms present in at least two vesicle populations. J Biol Chem 264: 12358-12363

16. Fukumoto H, Kayano T, Buse JB et al. (1989) Cloning and characterization of the major insulin-responsive glucose transporter expressed in human skeletal muscle and other insulin-responsive tissues. J Biol Chem 264: 7776-7779

17. Bell GI, Kayano T, Buse JB et al. (1990) Molecular biology of mammalian glucose transporters. Diab Care 13: 198-208

18. Cushman SW, Wardzala LJ (1980) Potential mechanism of insulin action on glucose transport in the isolated rat adipose cell. J Biol Chem 255: 4758-4762

19. Suzuki K, Kono T (1980) Evidence that insulin causes translocation of glucose transport activity to the plasma membrane from an intracellular storage site. Proc Natl Acad Sci USA 77: 25422545

20. Mühlbacher C, Karnieli E, Schaff P et al. (1988) Phorbol esters imitate in rat fat cells the full effect of insulin on glucose carrier translocation but not on 3-O-methylglucose transport activity. Biochem J 249: 865-870

21. Obermaier-Kusser B, Mühlbacher C, Mushack J, Rattenhuber E, Fehlmann M, Häring HU (1989) Regulation of glucose carrier activity by $\mathrm{AlCl}_{3}$ and phospholipase C in fat cells. Biochem $\mathrm{J} 256$ : $515-520$

22. Obermaier-Kusser B, Mühlbacher C, Rattenhuber E et al. (1988) Further evidence for a two step model of glucose transport regulation. Biochem J 261: 699-705

23. Garvey WT, Huecksteadt TP, Matthei S, Olefsky JM (1988) Role of glucose transporters in the cellular insulin resistance of the type II non-insulin dependent diabetes mellitus. J Clin Invest 81 : 1528-1536

24. Tanti JF, Rochet N, Gremeaux Th, VanObberghen E, LeMarchand-Brustel $Y$ (1989) Insulin stimulated glucose transport in muscle. Biochem J 258: 141-146

25. Klip A, Ramlal T, Young AD, Holloszy JO (1987) Insulin-induced translocation of glucose transporters in rat hindlimb muscles. FEBS Lett 224: 224-230

26. Klip A. Ramlal T, Bilan PJ, Cartee GD (1990) Recruitment of GLUT 4 glucose transporters by insulin in diabetic rat skeletal muscle. Biochem Biophys Res Commun 172; 728-736

27. Ploug $T$, Galbo H, Vinten $J(1988)$ Stimulation of glucose transport in skeletal muscle by insulin and contractions is caused by redistribution of glucose transporters in the plasma membrane. Diabetologia 29:570 A-571 A (Abstract)

28. Dohm GL, Tapscott EB, Pories WJ et al. (1988) An in vitro human muscle preparation suitable for metabolic studies. J Clin Invest 82: 486-494 
29. Garvey WT, Huecksteadt TP, Birnbaum MJ (1989) Pretranslational suppression of an insulin-responsive glucose transporter in rats with diabetes mellitus. Science $245: 60-63$

30. Berger J, Biswas C, Vicario PP, Stout HV, Saperstein R, Pilch PF (1989) Decreased expression of the insulin-responsive glucose transporter in diabetes and fasting. Nature $340 \div 70-72$

31. Walker PS, Ramlal T, Sarabia V et al. (1990) Glucose transport activity in L6 muscle cells is regulated by the coordinate control of subcellular glucose transporter distribution, biosynthesis and mRNA transcription. J Biol Chem 265: 1516-1523

32. Handberg A, Vaag A, Damsbo P, Beck-Nielsen H, Vinten J (1990) Expression of insulin regulatable glucose transporters in skeletal muscle from Type 2 (non-insulin-dependent) diabetic patients. Diabetologia 33: 625-627

33. Pedersen O, Bak JF, Andersen PH, Lund S et al. (1990) Evidence against altered expression of GLUT 1 or GLUT 4 in skeletal muscle of patients with obesity or NIDDM. Diabetes 39: 865 870

34. Avruch J, Wallach DEH (1971) Erythrocyte membrane adenosine triphosphatase activities in patients with endogenous depression and healthy subjects. Biochim Biophys Acta 233: 334 347

35. Verdon B, Berger E (1983) Galactosyltransferase. In: Bergmeyer B (ed) Methods of enzymatic analysis, Vol. 3. Verlag Chemic, Weinheim, pp 374-381

36. Karnieli E, Zarnowski MJ, Hissin PJ, Simpson JA, Salans LB, Cushman SW (1981) Preparation and characterization of plasma membrane fraction from isolated rat fat cells. J Biol Chem 256 : $4772-4777$

37. Vogt B, Mushack J, Seffer E, Häring HU (1990) The phorbol ester TPA induces a translocation of the insulin sensitive glucose carrier (GLUT 4) in fat cells. Biochem Biophys Res Commun 168: 1089-1094

38. Vogt B, Mushack J, Seffer E, Häring HU (1991) The translocation of the glucose transporter sub-types GLUT 1 and GLUT 4 in isolated fat cells is differently regulated by phorbol ester. Biochem J 275: 596-600

39. Friedman JE, Dudek RW, Whitehead DS et al. (1991) Immunolocalization of glucose transporter GLUT 4 within human skeletal muscle. Diabetes 40: $150-154$

Received: 16 September 1991

and in revised form: 27 December 1991

\section{Dr. H.Häring}

Klinisch-experimentelle Abteilung

Institut für Diabetesforschung

Kölner Platz 1

W-8000 München 40

FRG 